\title{
TO QUANTIFY THE LUTEOLIN CONTENT FROM THE AERIAL PARTS OF HETEROPOGON CONTORTUS (L.) BEAUV. (SPEAR GRASS) THROUGH HIGH-PERFORMANCE THIN-LAYER CHROMATOGRAPHY
}

\author{
NAVJOT KAUR*, RAGHBIR CHAND GUPTA \\ Department of Botany, Punjabi University, Patiala - 147 002, Punjab, India. Email: navjot21188@gmail.com \\ Received: 21 August 2017, Revised and Accepted: 09 October 2017
}

\section{ABSTRACT}

Objective: The objective of this study was to quantify the luteolin content present in the extracts from different aerial plants (leaves, stem, and inflorescence) of Heteropogon contortus through high-performance thin-layer chromatography.

Methods: The chromatographic fingerprint analysis of the different plant extracts has been developed using optimized mobile phase toluene: ethyl acetate: formic acid (5:5:0.7 v/v) and the developed plate is derivatized with freshly prepared anisaldehyde-sulfuric acid. Then, the plate is heated at $110-120^{\circ} \mathrm{C}$. The plate is scanned for densitometry measurements and to record the overlay spectra at $366 \mathrm{~nm}$ absorbance/reflectance wavelength. Quantification of luteolin marker compound in different extracts of H. contortus is estimated using 2-12 ng/spot.

Results: The yellow colored bands appearing on the chromatogram confirm the presence of luteolin marker compound in the different plant samples of $H$. contortus. Further, the presence of the luteolin marker is confirmed by comparing the $\mathrm{R}_{\mathrm{f}}$ values $(0.21)$ of the standard and the samples and from densitometry measurements by scanning the plate at $366 \mathrm{~nm}$ absorbance/reflectance. Line-to-line overlay spectra are obtained.

Conclusion: From this, it is concluded that leaf sample of $H$. contortus contains maximum amount of luteolin, i.e., $37.13 \pm 0.11$ mg/g of dry wt. than inflorescence $(1.60 \pm 0.013 \mathrm{mg} / \mathrm{g}$ of dry wt.) and stem $(0.53 \pm 0.014 \mathrm{mg} / \mathrm{g}$ of dry wt.). The leaves are good source of luteolin and can be used as an alternate natural source to synthesize herbal drugs to cure cancer, hypertension, and inflammatory diseases.

Keywords: Heteropogon contortus, Flavonoid, Luteolin, Different plant samples.

(c) 2018 The Authors. Published by Innovare Academic Sciences Pvt Ltd. This is an open access article under the CC BY license (http://creativecommons. org/licenses/by/4. 0/) DOI: http://dx.doi.org/10.22159/ajpcr.2018.v11i1.22116

\section{INTRODUCTION}

Flavonoids are a diverse group of polynutrients found in almost all fruits (apples and berries), onion, tea, vegetables, and some beverages. Quercetin and kaempferol are the best-known flavonoids. Natures' biological compounds are flavonoids that have the characteristics to modify the reactions taking place in the human body due to allergies, viruses, and carcinogens [1]. Quercetin and kaempferol are used as antioxidants and are investigated for inhibition of carcinogenicity [2]. Luteolin is an important flavonoid with a yellow crystalline appearance. It is found in vegetables and fruits such as celery, broccoli, onion leaves, carrots, peppers, cabbages, and apple skin and Chrysanthemum flowers [3-5]. Luteolin rich plants have been used in medicines to prevent hypertension, inflammatory diseases, and cancer [6]. The molecular structure of luteolin is given below (Fig. 1).

Heteropogon contortus (L.) Beauv. (Syn. Andropogon contortus L.) is a member of the family Poaceae (Gramineae), distributed in Southern Asia, Southern Africa, and Northern Australia. The spear grass is reported to have myo-inositol, galactinol, raffinose, and polysaccharides $[7,8]$. The grass exhibits medicinal importance as used in toothache, fever, atrophy, emaciation, muscular pain, hematological disorders, dysentery, and scorpion sting $[9,10]$. Roots of the plant have diuretic and stimulant properties. The whole plant is used to cure asthma [11].

The earlier studies observed that the methanolic extract of $H$. contortus is used for the treatment of pathological infections caused by mast cell destabilization, membrane destabilization, and free radical generation. It mainly includes acute and chronic inflammatory response such as asthma, arthritis, cardiovascular, and neural diseases. H. contortus extract inhibits bronchoconstriction induced by histamine or acetylcholine [12]. It also hinders inflammation induced by carrageenan and egg albumin. High-performance thin-layer chromatography (HPTLC) method was developed for the simultaneous quantification of luteolin and apigenin from Cardiospermum halicacabum and Hydnocarpus pentandra [13]. The main aim of the present research is to develop chromatographic fingerprint analysis of luteolin compound present in methanolic extracts of leaves, stem, and inflorescence of H. contortus.

\section{METHODS}

\section{Standard marker}

Luteolin is used as a reference standard for HPTLC. For chemical compounds, collection of plant material and sample preparation, preparation of stock solution, and thin-layer chromatography are seen [14].

\section{Detection and estimation of luteolin}

The linear fingerprint development was carried out in presaturated twin trough chamber $(20 \mathrm{~cm} \times 10 \mathrm{~cm})$ with toluene:ethyl acetate: formic acid (5:5:0.7 v/v) used as mobile phase. The length of the chromatogram was carried out up to a distance of $75 \mathrm{~mm}$. The plate was dried with hair drier and was then dipped in the freshly prepared anisaldehyde-sulfuric acid for derivatization. Then, the plate was heated at $110-120^{\circ} \mathrm{C}$ in hot air oven. Yellow colored bands appear on the plate. For the quantitative estimation of luteolin, the plate was scanned in absorption-reflection mode at $366 \mathrm{~nm}$ with $100 \mu \mathrm{m} / \mathrm{step}$ data resolution and at $20 \mathrm{~mm} / \mathrm{s}$ scanning speed.

\section{Method validation}

The method is validated as per ICH guidelines. Specificity, linearity, limit of detection (LOD) and quantification, precision, accuracy, robustness, 
and stability were checked for confirming method validation (Table 1). All the parameters were performed in triplicates [15].

LOD and limit of quantification (LOQ)

$$
\begin{aligned}
& \mathrm{LOD}=3.3 \frac{\mathrm{SD}}{\mathrm{S}} \\
& \mathrm{LOQ}=10 \frac{\mathrm{SD}}{\mathrm{S}}
\end{aligned}
$$

Where, SD stands for standard deviation, S for slope

\section{Recovery}

Recovery was determined by adding known concentrations of standard to a preanalyzed sample. The analysis was done by the proposed HPTLC method and the analysis was carried out in triplicate.

\section{Calibration curve of luteolin}

The standard stock solutions $(1 \mathrm{mg} / 1 \mathrm{ml})$ of luteolin $(2-10 \mu \mathrm{g} / \mathrm{spot})$ were applied in triplicate on an HPTLC plate. These plates were developed with the mobile phase toluene: ethyl acetate: formic acid (5:5:0.7 v/v). After development, the plates were air dried and scanned at $366 \mathrm{~nm}$ absorbance using deuterium lamp. The resolved peak area was recorded for the standard. The calibration curve of luteolin was plotted by taking peak area versus concentrations of standard.

\section{Method specification}

For luteolin, toluene: ethyl acetate:formic acid (5:5:0.7v/v) was used as a solvent system using silica gel $60 \mathrm{~F}_{254}$ precoated plates $(20 \mathrm{~cm} \times 10 \mathrm{~cm})$. Automatic Linomat $V$ application was used for spotting. The plates were developed in ascending mode up to $75 \mathrm{~mm}$ and scanned at $366 \mathrm{~nm}$ under UV-Vis mode. The content of luteolin in leaves, stem, and inflorescence of $H$. contortus was determined by comparing the peak area of standard luteolin with a calibration curve of $H$. contortus, considering the isolated compound to be $100 \%$ pure.

\section{RESULTS}

\section{Optimization}

At present, HPTLC fingerprint profile of luteolin and plant samples (leaves, stem, and inflorescence) has been developed under optimized chromatographic conditions using toluene: ethyl acetate: formic acid (5:5:0.7 v/v) as a mobile phase. Freshly prepared anisaldehyde-sulfuric acid is used as derivatizing reagent, and yellow colored bands have been observed during HPTLC profiling (Fig. 2). Then, the plates are scanned under UV-Vis absorbance/reflectance at $366 \mathrm{~nm}$ wavelength to obtain densitometry measurements (Fig. 3).

\section{Calibration curve and linearity}

The calibration curve was performed by plotting peak area versus concentration $(\mu \mathrm{g} / \mathrm{spot})$. The linear regression equation and correlation coefficient for luteolin are $y=6031.2 x$ and $R^{2}=0.99$. Thus, the graph obtained is linear (Fig. 4).

\section{Accuracy and recovery}

The presently obtained results showed that the average percentage recovery at three different levels of the luteolin compound is found 99.40\% (Table 1).
The highest amount of luteolin is present in leaves of the selected plant, i/e., $37.13 \pm 0.11 \mathrm{mg} / \mathrm{g}$ of dry wt. It is very low in stem sample, $0.53 \pm$ $0.014 \mathrm{mg} / \mathrm{g}$ of dry wt. and $1.60 \pm 0.013 \mathrm{mg} / \mathrm{g}$ of dry wt. in inflorescence. The calculated amount of luteolin presents in the different plant parts of $H$. contortus falls in the decreasing order of leaves $>$ inflorescence $>$ stem, i.e., $37.13>1.60>0.53 \mathrm{mg} / \mathrm{g}$ of dry wt. (Table 2 ).

The presently developed method is validated as per the ICH guidelines in terms of precision, repeatability, and accuracy (Table 3). The linearity range for luteolin was found to be $2-12 \mu \mathrm{g} /$ spot with 0.99 as a correlation coefficient and the obtained linear regression equation is $y=6031.2 x$ (set intercept zero). Linear calibration curves were obtained for the standard compound as described above. LOD value for standard compound is $0.015 \mathrm{ng} / \mathrm{spot}$, whereas, LOQ value is $0.04 \mathrm{ng} / \mathrm{spot}$.

\section{Specificity}

An overlain spectrum is recorded to check the identity and specificity of luteolin present in methanolic extracts of leaves, stem, and

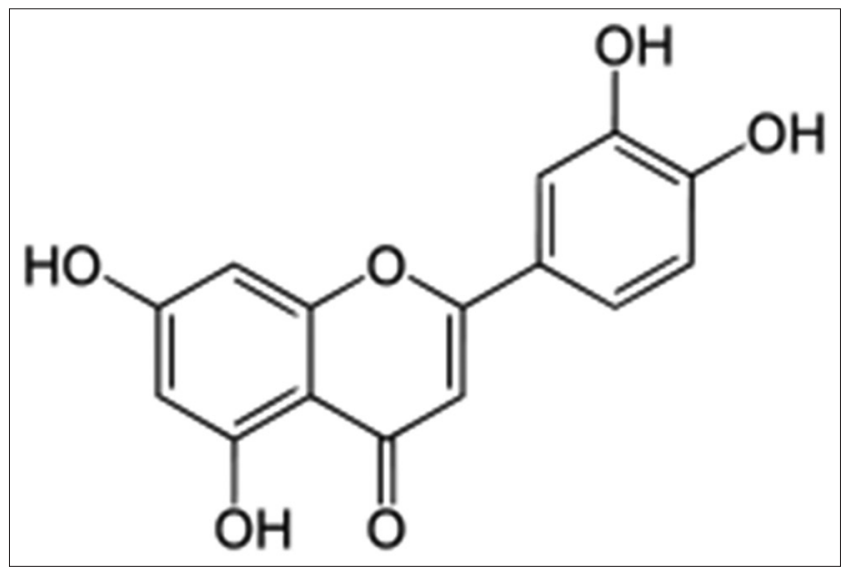

Fig. 1: Molecular structure of luteolin

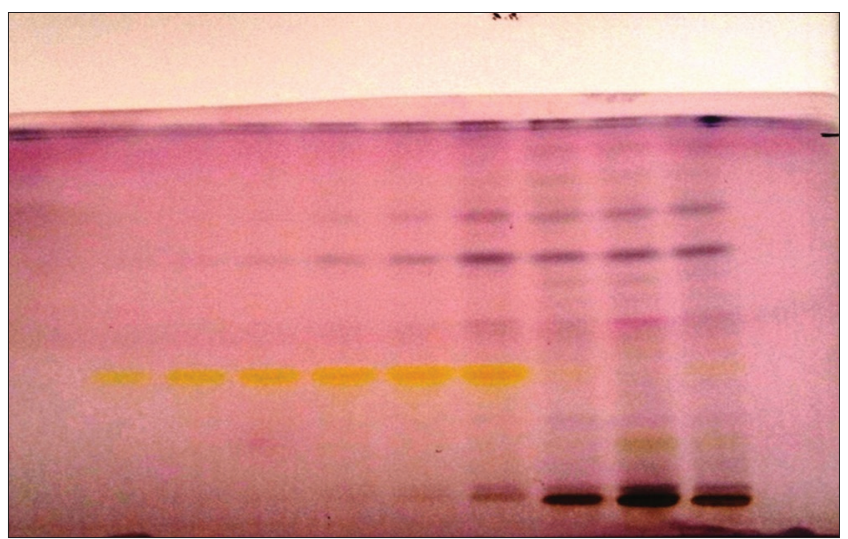

Fig. 2: High-performance thin-layer chromatography profile of luteolin (track 1-6) and methanolic plant samples of Heteropogon contortus (racks 7-9); 7 (HCLM), 8 (HCSM), and 9 (HCIM)

Table 1: Recovery study of luteolin by the proposed HPTLC method

\begin{tabular}{llllll}
\hline Marker compound & $\begin{array}{l}\text { Amount present } \\
\text { in sample }(\mu \mathrm{g})\end{array}$ & $\begin{array}{l}\text { Amount } \\
\text { added }(\mu \mathrm{g})\end{array}$ & $\begin{array}{l}\text { Theoretical } \\
\text { amount }(\mu \mathrm{g})\end{array}$ & $\begin{array}{l}\text { Amount } \\
\text { found }(\mu \mathrm{g})\end{array}$ & $\begin{array}{l}\text { Recovery (\%) } \\
\text { Average recovery (\%) }\end{array}$ \\
\hline Luteolin & 35 & 25 & 60 & 59.2 & 98.66 \\
& 35 & 29 & 64 & 65 & 101.56 \\
& 35 & 35 & 70 & 68.6 & 98 \\
\hline
\end{tabular}

HPTLC: High-performance thin-layer chromatography 


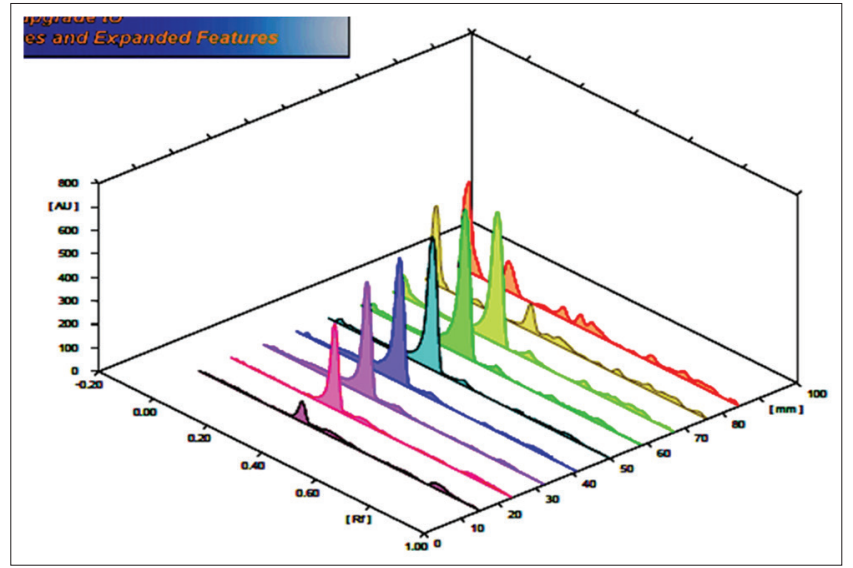

Fig. 3: Densitometric chromatogram of luteolin (track A-F) and plant samples of Heteropogon contortus (track G-I) HCLM, HCSM, and HCIM $\left(\lambda_{\max } 366 \mathrm{~nm}\right)$ (3D view)

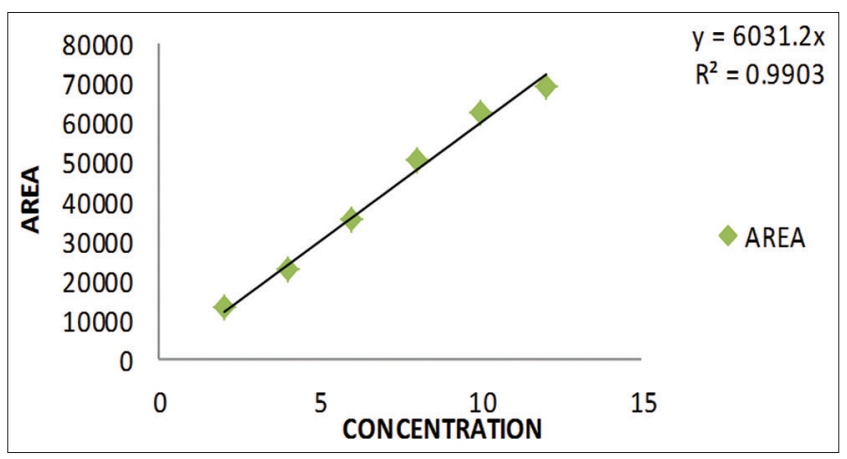

Fig. 4: Calibration curve of luteolin

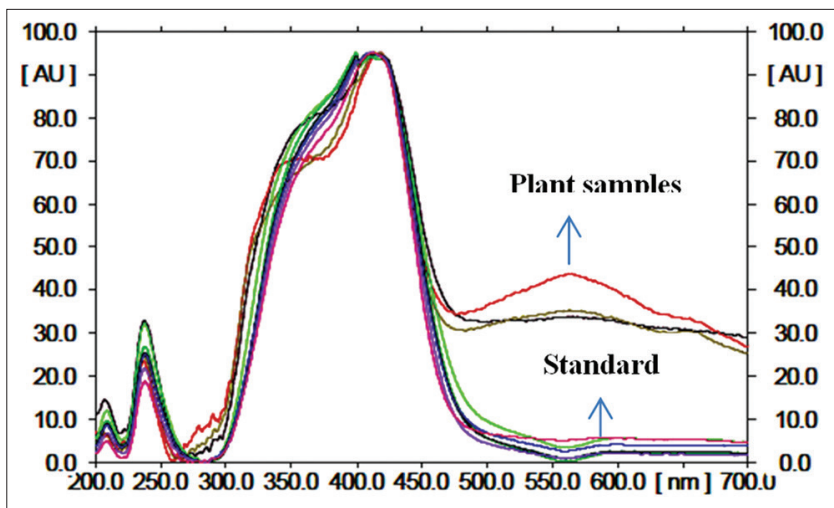

Fig. 5: Absorption spectra of luteolin and plant samples of Heteropogon contortus (HCLM, HCSM, and HCIM)

inflorescence of $H$. contortus. The spectrum of luteolin compound with the corresponding plant samples matches exactly. It indicates that there is no interference of the other herbal constituents. A line-to-line overlain spectrum between the standard and the three plant samples is recorded. This shows that the present method is specific (Fig. 5).

\section{DISCUSSION}

The developed method has been found to be sensitive, accurate, precise, specific, and robust for the screening and quantification of luteolin. HPTLC is still an effective tool for quality evaluation of medicinal plants, due to its simplicity, low cost, and low requirements. Hence, from the above obtained data, it is clear that $H$. contortus is a good source of flavonoid, i.e., luteolin, and thus the leaves of the species
Table 2: Quantification of luteolin from different plant parts of H. contortus

\begin{tabular}{lll}
\hline Plant parts & Sample codes & $\begin{array}{l}\text { Amount of luteolin in plant } \\
\text { sample }(\% \mathbf{w} / \mathbf{w})\end{array}$ \\
\hline Leaves & HCLM & $37.13 \pm 0.11$ \\
Stem & HCSM & $0.53 \pm 0.014$ \\
Inflorescence & HCIM & $1.60 \pm 0.013$ \\
\hline H. contortus: Heteropogon contortus
\end{tabular}

H. contortus: Heteropogon contortus

Table 3: Method validation parameters for the simultaneous quantification of luteolin

\begin{tabular}{ll}
\hline Parameters & Luteolin \\
\hline Wavelength $(\mathrm{nm})$ & 366 \\
$\mathrm{Rf}$ & 0.21 \\
Selectivity & Selective \\
Specificity & Specific \\
Linearity range $(\mu \mathrm{g} / \mathrm{spot})$ & $2-12$ \\
Correlation coefficient $\left(\mathrm{R}^{2}\right)$ & 0.99 \\
Linear regression equation $(\mathrm{y})$ & $6031.2 \mathrm{x}$ \\
LOD (ng/spot) & 0.015 \\
LOQ (ng/spot) & 0.04 \\
Accuracy (average \% recovery) & 99.40 \\
\hline
\end{tabular}

LOD: Limit of detection, LOQ: Limit of quantification

can be used in pharmaceutical industries. The flavonoids are known to play modulatory role in almost all neural pathways involved in the pathogenesis of epilepsy. Some of the important flavonoids are hispidulin, rutin, hesperetin, naringenin, eriodictyol, chrysin, gossypin, apigenin, kaempferol, myricetin, quercetin, hoslundin, hoslundal, hoslunddiol, morine, amentoflavone, hyperoside, anghyperoside, epicatechin, rutin, silibin, luteolin, etc [16]. Thus, the present study of $H$. contortus on phytochemical analysis of luteolin exhibits medicinal importance.

\section{CONCLUSION}

During the present study, the maximum amount of luteolin is found in leaf extract $(36.90 \pm 0.11)$ of $H$. contortus rather than stem and inflorescence. The compound luteolin present in the plant sample is found pure and do not show interference of any other herbal constituents. HPTLC is validated and is the most accurate method for the quantification and identification of luteolin in medicinally important grass $H$. contortus.

\section{ACKNOWLEDGMENT}

The authors would like to express their profound gratitude and sincere appreciation to UGC-BSR Single Girl Child Fellowship (Award letter no. and dated. F7-152/2007 BSR; 16-12-2013) and DBT-IPLS project (Project no. BT/PR-4548/INF/22/146/2012) sanctioned to Punjabi University, Patiala, for using the facilities and financial support for this study. The authors are also thankful to Head, Department of Botany, Punjabi University, Patiala.

\section{REFERENCES}

1. Aiyelaagbe OO, Osamudiamen PM. Phytochemical screening for active compounds in Mangifera indica leaves from Ibadan, Oyo state. Plant Sci Res 2009;2:11-13.

2. Joshi C, Savai J, Varghese A, Pandita N. Validated HPTLC fingerprint analysis for simultaneous estimation of Quercetin, Kaempferol and Asiatic acid in leaves of two different chemotypes of Centella asiatica. Int Pharma Biol Res 2012;3:202-12.

3. Neuhouser ML. Dietary flavonoids and cancer risk: Evidence from human population studies. Nutr Cancer 2004;50:1-7.

4. Miean KH, Mohamed S. Flavonoid (myricetin, quercetin, kaempferol, luteolin, and apigenin) content of edible tropical plants. J Agric Food Chem 2001;49:3106-12. 
5. Mencherini T, Picerno P, Scesa C, Aquino R. Triterpene, antioxidant, and antimicrobial compounds from Melissa officinalis. J Nat Prod 2007;70:1889-94.

6. Harborne JB, Williams CA. Advances in flavonoid research since 1992 Phytochemistry 2000;55:481-504.

7. Blake JD, Richards GN. Polysaccharides of tropical pasture herbage-I, studies on the distribution of the major polysaccharide components of spear grass (Heteropogon contortus) during growth. Aust J Chem 1970;23:2353-60.

8. Beveridce RJ, Dekker RF, Richards GN, Tows M. Identification of myo-isositol, galactikol, and rbffixose in spear grass (Heteropogon contortus). Aust J Chem 1972;25:677-8.

9. Chopra RN, Nayar SL, Chopra IC. Glossary of Indian Medicinal Plants. New Delhi, India: Council of Scientific and Industrial Research; 1956. p. 259-61.

10. Kirtikar KR, Basu BD. Indian Medicinal Plants. Vol II. Deharadun, India: International Book Distributors; 1935. p. 1074-6.

11. Ghante MH, Bhusari KP, Duragkar NJ. Evaluation of Heteropogon contortus (L.) Beauv. methanolic extract for mast cell, cell membrane and free radical stabilization. Indo Am J Pharma Res 2012;2:1015-26.

12. Ghante MH, Bhusari KP, Duragkar NJ. Bronchorelaxent and antiinflammatory effect of Heteropogon contortus (L.) Beauv. Methanolic extract. Int J Pharm Tech Res 2013;5:99-104.

13. Shambhu N, Dighe V. Development, validation of HPTLC method for simultaneous quantitation of luteolin, apigenin from Cardiospermum halicacabum Linn. and Hydnocarpus pentandra (Buch-Ham.) Oken. Int J Pharm Pharm Sci 2014;6:408-12.

14. Kaur N, Gupta RC. Determination of sugar biomarkers in different plant parts of Lasiurus scindicus henrard (Poaceae) through high performance thin layer chromatography. Int J Sci Eng Res 2017;8:1237-49.

15. ICH Q2A. Text on Validation of Analytical Procedures. In: Proceedings of the International Conference on Harmonization of Technical Requirements for Registration of Pharmaceuticals for Human Use, Geneva; 1994.

16. Singh P, Singh D, Goel RK. Phytoflavonoids: Antiepileptics for the future. Int J Pharm Pharm Sci 2014;6:51-66. 